\title{
Repeat abortion: facts and issues
}

\author{
Sangeeta Das, Adewale Adegbenro, Susmita Ray, Olubusola Amu
}

\begin{abstract}
Background The commonest reason for undertaking termination of pregnancy (TOP) in the UK is as defined by Clause 2 of the Abortion Act. There are no agreed criteria for defining 'recurrent abortion seekers'. We aimed to review the characteristics of women requesting termination of at least two consecutive pregnancies within 24 months of the first and to identify any factors for seeking repeat TOP.
\end{abstract}

Methods The database of patients that attended our Fertility Control Services from 2001 to 2006 was evaluated. Demographic data, contraceptive use in the cycle of conception and reasons for request were assessed for possible associations with repeat TOP.

Results The incidence was $2.3 \%$ as defined by our criteria. Financial circumstances was the commonest reason for seeking TOP (75\%). The combined oral contraceptive pill and condom were the commonest forms of contraception in these patients before the first TOP (35\% and $38 \%$, respectively). Long-acting reversible contraception (LARC) was used by only $8 \%$ of women before their TOP. Although $58 \%$ accepted LARC following TOP, only $2 \%$ continued its use thereafter and $50 \%$ of women were not using any contraception at the time of the repeat TOP.

Conclusion This study suggests that social workers and perhaps psychologists should be part of the peri-abortion counselling team. Contraceptive counselling should emphasise the side effects of LARC to improve compliance. Follow-up to ensure compliance and involvement of partners in decision-making could help to reduce the incidence of repeat TOP.

Keywords abortion, emergency contraception, LARC, long-acting reversible contraception, repeat abortion

J Fam Plann Reprod Health Care 2009; 35(2): 93-95

(Accepted 20 August 2008)

\section{Introduction}

In England and Wales, abortion rates rose from 186400 in 2005 to 193700 in 2006. Despite the availability and easy accessibility of contraceptive services, one in four abortions in the UK was a repeat episode. ${ }^{1}$ The most common indication for abortion in the UK is Clause $\mathrm{C}$ of the Abortion Act 1967 (i.e. a pregnancy that threatens the mental or physical health of a woman). Generally, unwanted pregnancies result from lack of awareness of emergency contraception (EC) and poor compliance or improper use of contraception, with the user-dependent modalities worsening the situation. Most women undergoing an abortion will have had unprotected intercourse or will have been using a contraceptive method that has high failure rates associated with typical use, mainly condoms or combined contraceptive pills (COCs). ${ }^{2}$ Contraceptive methods that are independent of daily compliance for their effectiveness, such as long-acting reversible contraception (LARC), are associated with very low failure rates even with typical use but are used by less than $8 \%$ of women in the UK. 3,4 Moreover, for all methods of contraception, discontinuation rates are disappointingly high. ${ }^{5}$

We aimed to establish the rate of repeat abortion seekers within the population catered for by our pregnancy termination service and to compare the rate with similar services worldwide. We also aimed to use any specific characteristics identified to develop strategies to reduce repeat abortion. A review of the scientific literature indicated that there is a lack of consensus regarding the definition of 'repeat abortion'. Authors have used their own criteria to define repeat aborters, for example, Nguyen et

Department of Obstetrics and Gynaecology, Royal Oldham Hospital, Oldham, UK

Sangeeta Das, MRCOG, DFSRH, Specialist Registrar

Adewale Adegbenro, MBBCh, Senior House Officer

Susmita Ray, MRCOG, MFSRH, Consultant

Olubusola Amu, MRCOG, DFSRH, Consultant

Correspondence to: Dr Sangeeta Das, Department of Obstetrics and Gynaecology, Royal Bolton Hospital, Minerva Road, Bolton BL4 0JR, UK. E-mail: sangeetadas65@aol.com

\section{Key message points}

- Women under the age of $\mathbf{2 5}$ years are most likely to seek abortions in successive pregnancies.

- There are no clear criteria for defining women who seek repeat abortions. This group is as likely to be in a stable relationship as women undergoing only one abortion.

- Partner involvement in counselling could improve continuation of effective contraception.

al. ${ }^{6}$ and Millar et al. ${ }^{7}$ defined repeat aborters as women who had undergone at least one previous abortion. They did not define a specific time period between the two episodes. ${ }^{6,7}$ Conversely, Gispert et al.$^{8}$ defined their study population as women undergoing two abortions within a period of 2 years while Alouini et al. ${ }^{9}$ defined repeat aborters as women undergoing more than one abortion within a 12-month period. Rowlands has also acknowledged the absence of strict criteria defining 'repeat' abortion. ${ }^{10}$ Recent childbirth is a common reason for discontinuation of contraception. Women in such a situation would be more likely to seek an abortion in the event of an unwanted pregnancy. It would be logical then to assume that they would continue with their chosen contraceptive method rather than have a second or even third unwanted pregnancy during the ensuing 24-month period. We therefore defined the criteria for our study as undergoing more than one abortion within a 24-month period without any live birth occurring between the two abortion episodes.

\section{Methods}

A retrospective study was designed to investigate the incidence of repeat termination of pregnancy (TOP) in our local population. The computerised database was accessed to identify women who attended the Fertility Control Services at the Royal Oldham Hospital, Oldham, UK, a district general hospital, from April 2001 to March 2006 and who underwent two consecutive TOPs within 24 months. Demographic data were collected and analysed from case notes on a standard proforma. 
Table 1 Comparing demographic characteristics of the repeat aborters group $(n=40)$ at the time of the first and repeat abortions

\begin{tabular}{lll}
\hline Characteristic & $\boldsymbol{n}$ & $\boldsymbol{p}$ \\
\hline Age & & \\
$\quad<25$ years & 30 & 0.002 \\
$\quad \geq 25$ years & 10 & \\
Parity & & \\
$\quad$ Nulliparous & 17 & NS \\
$\quad$ Multiparous & 23 & \\
Partner present & & \\
$\quad$ Yes at first TOP & 29 & NS \\
Yes at repeat TOP & 26 & NS \\
No at first TOP & 11 & 14 \\
No at repeat TOP & 14 & \\
\hline
\end{tabular}

NS, not significant; TOP, termination of pregnancy.

\section{Statistical analysis}

Statistical analysis was done using binomial distribution in the analyses for comparing variables within the cohort and the Chi-square test for comparing variables between the study and control groups. Statistical analysis employed StatsDirect software version 2.6.6 (StatsDirect Ltd, Altrincham, UK).

\section{Results}

During the study period 2034 women underwent TOP at the unit. Of these, 47 (2.3\%) were repeat terminations and 40 case notes were available for analysis. Thirty-eight women had undergone one repeat termination and two women had TOP three times within 24 months of the first TOP. None of the women had a live birth between the two TOP episodes. Of the women who underwent repeat TOP, a significant number were aged under 25 years (Table 1 ). This was also true of women who had one TOP during the same period, and the difference between the two groups was not statistically significant (Table 1). Twenty-three $(57 \%)$ women had other children at the time they requested TOP, while $17(43 \%)$ were nulliparous $(p=0.4)$ (Table 1$)$. There was no significant difference between the number of women who were with the same partner at the time of requesting the first or the repeat TOP (Table 1). This result was not significantly different when the study group was compared with all clients who had undergone TOP during the study period. Similarly, there was no significant difference in relationship stability between the study population and all clients (Table 2). The study population (women seeking repeat TOP) was more likely to be unemployed (either one or both partners) when compared with all clients seeking abortion, and this just reached statistical significance $(p=0.05)$ (Table 2).
Regarding contraception methods, $35 \%$ of women seeking a repeat abortion were using COCs at the time they requested the first TOP. Although only $28 \%$ intended using COCs after the first TOP, $55 \%$ had returned to using this method at the time they requested a repeat TOP. LARC was used by $8 \%$ of the women before the first TOP and acceptance of this method increased to $57.5 \%$ following the first TOP. However, only $2 \%$ of the women continued using LARC when they presented for repeat TOP. In contrast, women who underwent only one abortion during the study period were more likely to accept and continue using LARC $(n=1238,62.3 \%)$. Barrier contraceptive methods were the most commonly used method by these women: $38 \%$ of women used this method before their first TOP. Although none of these women intended using this method after their TOP, 25\% still continued with this method afterwards. Half of the women had reverted back to not using any form of contraception before the repeat TOP. Overall, only $5 \%$ of the women had accessed EC prior to accessing the abortion service.

\section{Discussion}

In this study, the majority of the women were aged under 25 years. Interestingly, women seeking repeat TOP were as likely to be in a stable relationship as those women having one TOP, which suggests that extending counselling to partners could improve compliance with the chosen method of contraception by sharing the responsibility. Howe et al. compared women who had undergone one abortion with those who had undergone two or more abortions and found that in addition to missing pills or having mishaps with condoms, non-use of contraception was an important reason for TOP. ${ }^{12}$ Similarly, in our study $50 \%$ of the women were not using any method of contraception before the repeat TOP.

Similar results to these are found in the scientific literature, for example, repeat aborters are more likely to discontinue contraception due to side effects and to be using COCs at the time of conception and less likely to be aware of EC. Several studies have concluded that financial and psychological factors are the two most common reasons for TOP. ${ }^{11-14}$ Discontinuation of LARC, in addition to one or both partner being unemployed, was the most common reason for seeking repeat TOP in our study.

Schneider and Thompson ${ }^{13}$ reported that $50 \%$ of women used contraception before whereas $70 \%$ commenced contraception only after their first abortion. One year before a repeat abortion only $13 \%$ of women were using contraception ${ }^{13}$. Our results echo these findings with $57.5 \%$ accepting LARC after abortion but only $2 \%$ continuing at second presentation for abortion, the most common cause for discontinuation being menstrual

Table 2 Comparators between repeat abortion seekers $(n=40)$ and clients who underwent one abortion during the study period $(n=1987)$

\begin{tabular}{llll}
\hline Comparator & $\begin{array}{l}\text { Repeat abortion seekers } \\
(\boldsymbol{n}=\mathbf{4 0})[\boldsymbol{n}(\%)]\end{array}$ & $\begin{array}{l}\text { Clients having one abortion only } \\
(\boldsymbol{n}=\mathbf{1 9 8 7 )}[\boldsymbol{n}(\%)]\end{array}$ & $\boldsymbol{p}$ \\
\hline Age $\leq 25$ years & $30(75.0)$ & $1212(61.0)$ & $\mathrm{NS}$ \\
Acceptance of LARC after first TOP & $23(57.5)$ & $1238(62.3)$ & $\mathrm{NS}$ \\
$\begin{array}{l}\text { Stable relationship } \\
\text { Yes }\end{array}$ & $26(65.0)$ & $1239(62.4)$ & $\mathrm{NS}$ \\
No & $14(35.0)$ & $748(37.6)$ & \\
Unemployed & $16(40.0)$ & $489(24.6)$ & 0.05 \\
\hline
\end{tabular}

LARC, long-acting reversible contraception; NS, not significant, TOP, termination of pregnancy. 
irregularities, as is widely published in the literature. Schumann and Glasier15 have shown that expert counselling increases LARC uptake but does not decrease the repeat abortion rate. This suggests that the initial response to expert counselling is positive, with a decline in motivation resulting in discontinuation of LARC.

Only $5 \%$ of our patients had accessed EC. Whilst EC should be used only in exceptional circumstances rather than routinely, EC could nevertheless prove very useful if the patient had a reasonable understanding of their indications and direction for use. ${ }^{16}$ It is clear that placing emphasis on EC awareness and availability during contraceptive counselling could help reduce the incidence of repeat TOPs.

Management of repeat abortion should go beyond just medical considerations and should consider the social, economic, cultural and psychological aspects of an individual woman. Studies have shown complex psychological factors to be a potent factor in nonacceptance or poor compliance with contraception. ${ }^{10,17,18}$ Schumann and Glasier in a randomised study have shown that directed expert counselling does not improve longterm continuation of contraceptive methods. ${ }^{14}$ Therefore, it is imperative that in addition to full medical counselling for contraception, psychological counselling and involvement of social workers where appropriate may be beneficial in tackling underlying psychosocial problems. In conjunction with this, the provision of follow-up to address concerns regarding the chosen contraceptive method, the involvement of partners in the decision-making process and the continuation of contraception could all help to reduce the incidence of abortion.

\section{Acknowledgement}

The authors would like to thank Mr S Murray of the Clinical Audit Department, Royal Oldham Hospital, Oldham, UK for collating the data.

\section{Statements on funding and competing interests \\ Funding None identified.}

Competing interests None identified.
References

1 Department of Health. Abortion Statistics, England and Wales: 2006. 2007. http://www.dh.gov.uk/en/publicationsandstatistics/ publications/publicationsstatistics/dh_075697? [Accessed 4 June 2008].

2 Garg M, Singh M, Mansour D. Peri-abortion contraceptive care: can we reduce the incidence of repeat abortions? J Fam Plann Reprod Health Care 2001; 27: 77-80.

3 Hatcher RA, Trussell J Stewart F, Nelson AL, Cates W Jr Guest F, et al. (eds). Contraceptive Technology (18th edn). New York, NY: Ardent Media Inc., 2004; 226.

4 Dawe F, Rainford L. Contraception and Sexual Health 2003. London, UK: Office for National Statistics, 2004.

5 Rosenberg MJ, Wangh MS, Burnhill MS. Unintended pregnancies and use, misuse, and discontinuation of oral contraceptives. J Reprod Med 1995; 40: 355-360.

6 Nguyen TM, Chongsuvivatwong V, Geater A, Prateepchaikul L. Characteristics of repeat aborters in Vietnam. Southeast Asian $J$ Trop Med Public Health 2000; 31: 167-172.

7 Millar WJ, Wadhera S, Henshaw SK. Repeat abortions in Canada, 1975-1993. Fam Plann Perspect 1997; 29: 20-24.

8 Gispert M, Brinich P, Wheeler K, Krieger L. Predictors of repeat pregnancies among low-income adolescents. Hosp Community Psychiatry 1984; 35: 719-723.

9 Alouini S, Uzan M, Meningaud JP, Herve C. Knowledge about contraception in women undergoing repeat voluntary abortions, and means of prevention. Eur J Obstet Gynaecol Reprod Biol 2002; 104: 43-48.

10 Rowlands S. More than one abortion. J Fam Plann Reprod Health Care 2007; 33: 155-158.

11 Fisher WA, Singh SS, Shuper PA, Carey M, Otchet F, MacLean-Brine D, et al. Characteristics of women undergoing repeat induced abortion. Can Med Assoc J 2005; 172: 637-641.

12 Howe B, Kaplan R, English C. Repeat abortion: blaming the victims. Am J Public Health 1979; 69: 1242-1246.

13 Schneider SM, Thompson DS. Repeat aborters. Am J Obstet Gynecol 1976; 126: 316-320.

14 Westfall JM, Kallail KJ. Repeat abortion and use of primary care health services. Fam Plann Perspect 1995; 27: 162-165.

15 Schumann C, Glasier A. Specialist contraceptive counselling and provision after termination of pregnancy improves uptake of long-acting methods but does not prevent repeat abortion: a randomised trial. Hum Reprod 2006; 21: 2296-2303.

16 Bracken MB, Hachamoritch M, Grossman G. Correlates of repeat induced abortions. Obstet Gynecol 1972; 40: 816-825.

17 Blumfield M. Psychological factors involved in request for elective abortions. J Clin Psychiatry 1978; 39: 17-25.

18 Ogden J. Health Psychology: A Textbook (3rd edn). Buckingham, UK: Open University Press, 2004.

\section{BOOK REVIEWS}

Contraception: A History. Robert Jütte (English translation by Vicky Russell). Oxford, UK: Polity Press, 2007. ISBN-13: 978-0745632711. Price: £18.99. Pages: 288 (paperback)

Despite its title, this book covers a tremendous amount. It examines attitudes towards sexuality and contraception, as well as the various means by which people have tried to control their fertility through the ages. It looks at the attitudes and behaviour of those who opposed any controls or restriction on the policy of "go forth and multiply", as well as those who turned a blind eye to what people did, and those who encouraged the use and spread information about contraception.

The book contains so much that it is impossible to summarise. Much of its content was new to me, despite my many years immersed in the literature around contraception. It provides considerable ammunition for those opposed to illogical thought or who need to reply to those who rely on so-called "traditional beliefs". The author starts with 429 BC. He quotes Plato and Aristotle (who both debated birth control) and finishes with a debate about the role of the male pill today.

The author also covers the publication in 1900 of an early clinical trial from Mensinga, an influential medical campaigner for birth control in Germany. Mensinga reported the use of his pessary (diaphragm) in "a dozen of my female patients who, wholly aware of its purpose, have been assisting me in my reliability project". Mensinga reported that all of the patients, two from the upper class, four from the middle class and six from the working class, had been using the pessary with success for more than 4 years. Sophisticated stuff! Robert Jütte also details the opposition of the medical publications in the UK at the time, fulminating against the unnatural practice of contraception.

It was interesting to read that in the 18th and 19th centuries the USA was very agains contraception and passed laws whereby it was illegal to pass on information about contraception even, in some states, by word of mouth. And that these regulations were not lifted until 1965! By comparison, even the Catholic Church was less draconian. They only suggested that the priest should "not enquire directly about it in the oral confessional"! And many other countries had legislation about the publication of information about contraception, ignored or flouted by the valiant campaigners.

The inclusion of information from so many sources and countries about contraception techniques, information and the battles for the freedom of the woman to choose is staggering. The index is excellent, making it easy to look things up Not a light read, but an excellent resource book (lots of references) and provoking much thought.

Reviewed by Gill Wakley, MD, FFSRH

Advisory Editor, Journal of Family Planning and Reproductive Health Care
Problem Solving in Women's Health. Margaret Rees, Sally Hope, Martin K Oehler, Jane Moore and Polly Crawford. Oxford, UK: Clinical Publishing, 2008. ISBN-13: 978-1-84692-028-8. Price: £35.00. Pages: 244 (paperback)

This is an interesting book dealing with conditions that women usually present with in primary care. The book is divided into eight main sections: menstrual problems, menopause, fertility and contraception, gynaecological emergencies, sexual problems, urogenital problems, prevention and screening, and gynaecological cancer. Background information is followed by investigations, management, medical options, recent developments and conclusions. A case history and further reading are also presented in each instance, which helps to clarify the condition very well. The book is well laid out with clear headings and text that is easy to read. Each condition discussed is between two and four pages long, thus giving useful advice at a glance if information about a particular problem is required quickly. The clarity and succinctness of the book make it particularly useful for busy health care professionals working in primary care, including general practice, NHS walk-in centres and sexual health clinics.

\section{Reviewed by Lucy Bunting, RGN}

Health Visitor and Sexual Health Nurse, Heart of Birmingham Teaching Primary Care Trust (HoBTPCT), Birmingham, UK 